\title{
System Modeling of a Novel Aluminum Fueled UUV Power System
}

\author{
W. Ethan Eagle \\ University of Michigan, Ann Arbor, MI, 48109 \\ Daniel F. Waters ${ }^{\dagger}$ and Christopher P. Cadou ${ }^{*}$ \\ University of Maryland, College Park, MD, 20740
}

A thermodynamic model is developed for a novel underwater propulsion system called a hybrid aluminum combustor (HAC) that is based on the exothermic reaction of aluminum powder with sea water. The Rankine cycle-based propulsion system's components are created and linked together using a system modeling tool called Numerical Propulsion System Simulation (NPSS). The results of the system simulation show that replacing batterybased power systems in unmanned underwater vehicles (UUVs) with HAC-based systems could increase range and endurance by factors of 2 to 5 . A rudimentary sensitivity analysis indicates that overall system efficiency is maximized by adjusting the ratio of water mass flow to fuel mass flow so as to control the temperature and quantity of steam. The results also indicate that increasing the amount of combustion byproduct, hydrogen, improves the performance of the turbine. However, the thermodynamic costs of compressing the hydrogen can be high. More work is required to assess the impacts of frictional, thermal, hydrogen compression, and component integration losses on power output and efficiency.

\section{Nomenclature}

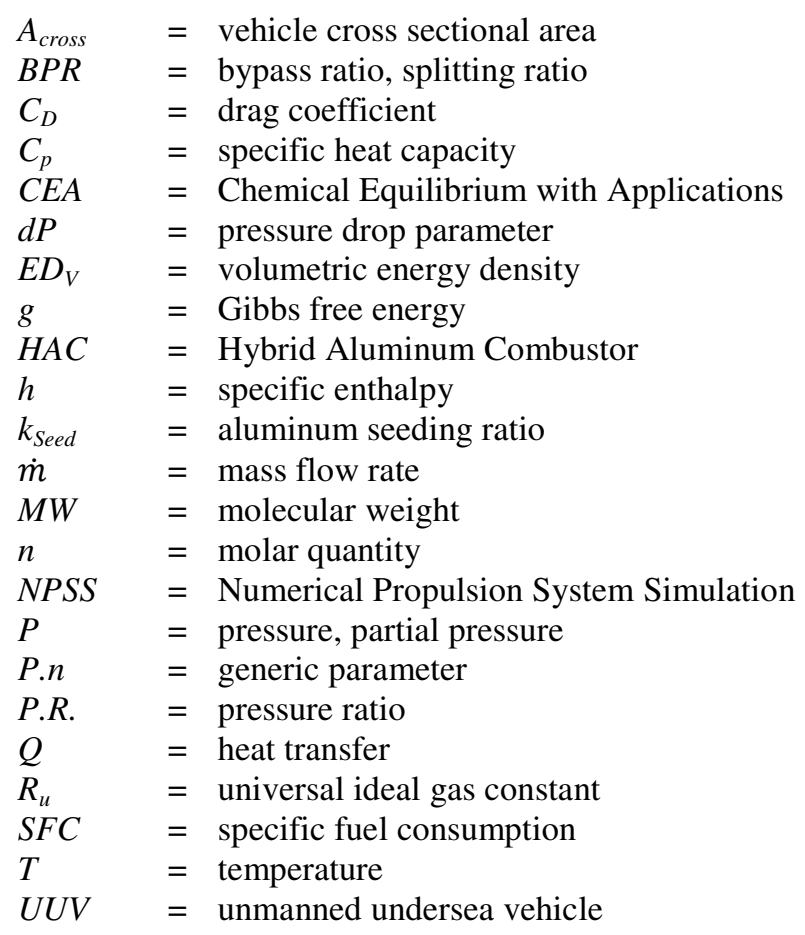

\footnotetext{
${ }^{*}$ Ph.D. Candidate, Department of Aerospace Engineering, AIAA Student Member.

${ }^{\dagger}$ Graduate Research Assistant, Department of Aerospace Engineering, AIAA Student Member.

* Associate Professor, Department of Aerospace Engineering, AIAA Associate Fellow.
} 


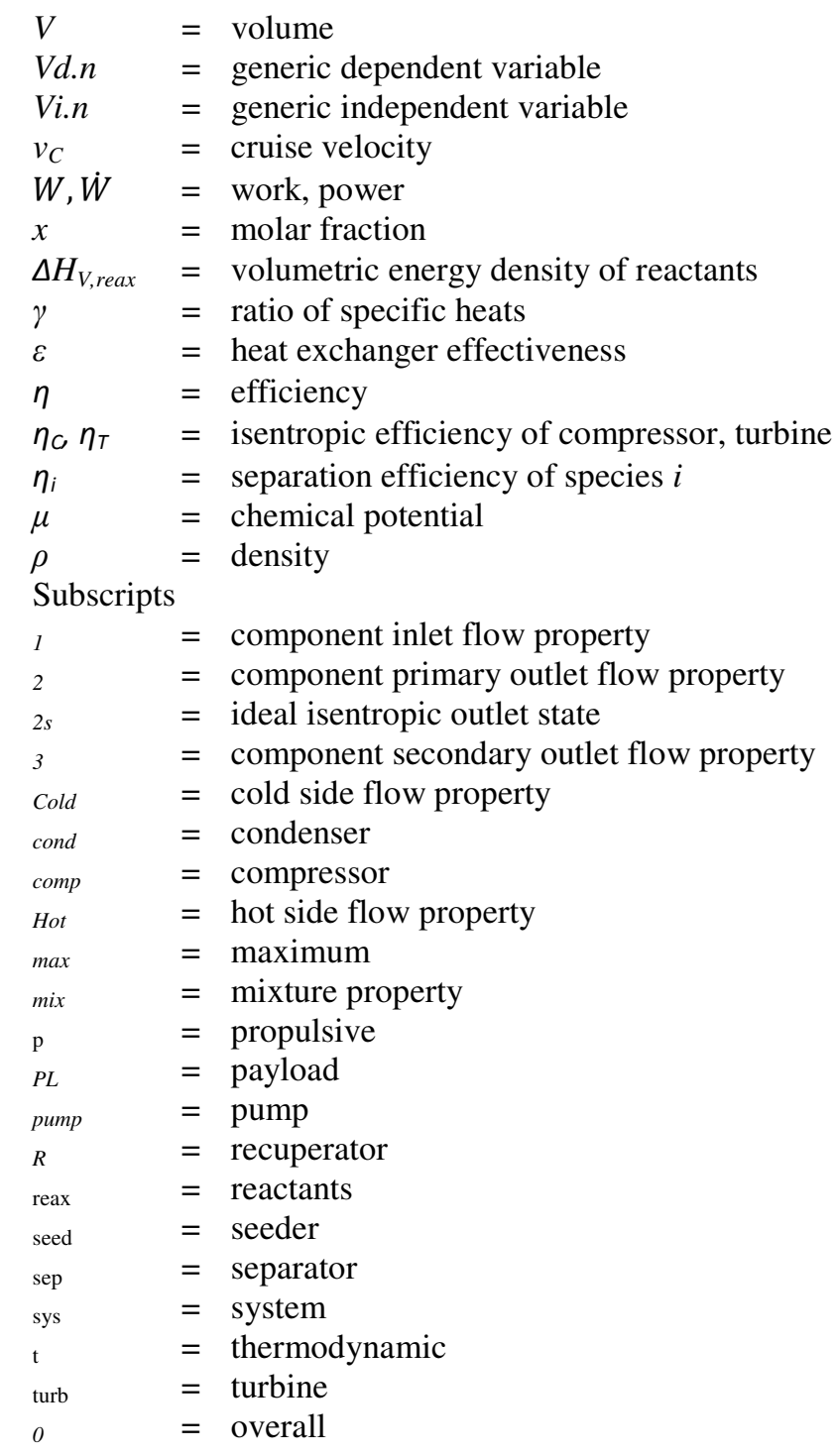

\section{Motivation}

THE United States Navy has a growing need for advanced Unmanned Undersea Vehicles (UUVs) that can perform critical missions while keeping sailors out of harm's way. Several key naval missions including intelligence, surveillance, and reconnaissance, have been identified as best performed by UUVs ${ }^{1}$. The range of a UUV at constant speed and depth is given $b^{2}$ :

$$
\text { Range }=\frac{\eta_{0} \cdot \Delta H_{V, \text { reax }} \cdot V_{\text {reax }}}{\left(\dot{W}_{P L} / v_{C}\right)+\left(\frac{1}{2} \rho_{\text {seawater }} v_{C}^{2}\right) \cdot\left(C_{D} A_{\text {cross }}\right)}
$$

where $\eta_{0}$ is the overall efficiency which is the product of the thermodynamic and propulsive efficiencies $\left(\eta_{0}=\eta_{t} \eta_{p}\right)$, $\Delta H_{V, \text { reax }}$ is the volumetric energy density (energy per unit volume) of the reactants, $V_{\text {reax }}$ is the volume of the stored reactants, $\dot{W}_{P L}$ is the payload power, $C_{D}$ is the vehicle's drag coefficient, and $A_{\text {cross }}$ is the vehicle cross-section area. Equation (1) shows that the range of existing UUVs is limited by the volumetric energy density of the power/energy system and the overall conversion efficiency of the power system. Current electrochemical energy sources have relatively low energy densities $\left(180-315 \mathrm{~W}-\mathrm{hr} / \mathrm{L}\right.$ for Li-ion $\left.{ }^{3,4}\right)$ which means that the range of today's electrically 
powered UUVs - and consequently their operational capability - is limited ${ }^{1}$. Replacing electrochemical 'fuels' with solid metals that react exothermically with water harvested from the environment (in the same way that aircraft engines harvest oxygen from the air) could greatly increase system-level energy density and lead to significant improvements in operational capabilities provided acceptable levels of thermodynamic efficiency can be achieved.

\section{A. Previous Work}

\section{Background}

Significant efforts were made in the 1960s to find higher energy density replacements for Otto fuel in torpedoes ${ }^{5}$. Metals like aluminum $(\mathrm{Al})$, zirconium $(\mathrm{Zr})$, magnesium $(\mathrm{Mg})$, and lithium $(\mathrm{Li})$ that react exothermically with water were of particular interest ${ }^{5,6}$ because of their high energy densities. Table 1 compares the energy contents of several

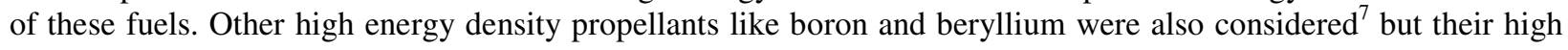
cost and/or toxicity make them impractical for shipboard use and so they are not included in the table. Unlike aircraft where lift-induced drag makes vehicle weight a key restriction, underwater vehicles are primarily influenced by skin drag and form drag (both heavily dependent on the vehicle's physical dimensions) and lift-induced drag can usually be neglected ${ }^{8}$. Therefore, volume is the primary consideration and volumetric energy density is the most important metric. By this measure the $\mathrm{Al} / \mathrm{H}_{2} \mathrm{O}$ reaction offers the highest theoretical performance ${ }^{9}$ at $11374 \mathrm{~W}-\mathrm{hr} / \mathrm{L}$. The $\mathrm{Al} / \mathrm{H}_{2} \mathrm{O}$ reaction has also been investigated as a means of increasing energy density and enhancing combustion stability in high pressure rockets. These studies focused on the practicality of storing and fluidizing powdered aluminum for rocket applications ${ }^{10}$ and on the chemical evolution of the $\mathrm{Al} / \mathrm{H}_{2} \mathrm{O}$ reaction ${ }^{11}$.

Table 1. Energy content of various undersea propulsion reactant combinations.

\begin{tabular}{|c|c|c|c|}
\hline Fuel & Oxidizer & $\begin{array}{c}\text { Specific } \\
\text { Energy } \\
(\mathrm{W}-\mathrm{hr} / \mathrm{kg})\end{array}$ & $\begin{array}{c}\text { Energy } \\
\text { Density, } \Delta H_{V} \\
\text { (W-hr/L) }\end{array}$ \\
\hline $\mathrm{Al}$ & $\mathrm{H}_{2} \mathrm{O}$ & 4212 & 11374 \\
\hline $\mathrm{Zr}$ & $\mathrm{H}_{2} \mathrm{O}$ & 1611 & 10503 \\
\hline $\mathrm{Al}$ & $\mathrm{LiClO}_{4}$ & 3523 & 8898 \\
\hline $\mathrm{Mg}$ & $\mathrm{H}_{2} \mathrm{O}$ & 3609 & 6273 \\
\hline $\mathrm{Li}$ & $\mathrm{H}_{2} \mathrm{O}$ & 7969 & 4256 \\
\hline \multicolumn{2}{|c|}{ Otto fuel $^{5}$} & 705 & 895 \\
\hline \multicolumn{2}{|c|}{ Li-ion batteries ${ }^{3,4}$} & $90-130$ & $180-315$ \\
\hline \multicolumn{2}{|c|}{ Alkaline batteries ${ }^{12}$} & $110-200$ & $150-270$ \\
\hline \multicolumn{2}{|c|}{$\mathrm{Pb}$-acid batteries ${ }^{12}$} & $70-120$ & $30-60$ \\
\hline
\end{tabular}

However, the energy density of the propellant is not the only important factor as improvements in range will only be realized if the chemical potential energy stored in the $\mathrm{Al}$ is converted to propulsive power efficiently and the mass/volume of the energy conversion system is not so large that it effectively eliminates the energy density advantage of the energy storage materials. Therefore, the important metric is really the effective energy density of the power and energy system (i.e. the total recoverable energy in the stored propellant times the overall thermodynamic efficiency of the conversion system divided by the fuel and conversion system volume) not the energy density of the propellant itself. The effective energy density is given by:

$$
E D_{V}=\eta_{t} \cdot \Delta H_{V, \text { reax }} \cdot \frac{V_{\text {reax }}}{V_{\text {sys }}}
$$

where $V_{\text {reax }}$ and $V_{s y s}$ are the reactant and overall system volumes respectively. The tradeoff between energy density and thermodynamic efficiency is illustrated in Figure 1. The dashed lines show contours of constant range computed using Equation (1). The red and green crosses correspond to the upper and lower ends of the Li-ion battery performance range. The solid triangles show the minimum thermodynamic conversion efficiency that an ideal HAC system (where $V_{\text {reax }} / V_{s y s} \approx 1$ ) would need to achieve in order to match the performance of battery-based systems $(2.6 \%)$ and increase performance by a factor of $10(26 \%)$.

Previous work suggests that it is possible to build metal combustion based systems that are suitably efficient and compact to realize significant improvements in range and endurance. Studies by Greiner in 1970 predicted a fourfold increase in range could be achieved by utilizing the $\mathrm{Al} / \mathrm{H}_{2} \mathrm{O}$ reaction in a high speed (torpedo) system ${ }^{13}$. Modern torpedo-borne Rankine-cycle steam turbines achieve efficiencies of over thirty percent indicating that a ten-fold increase in range could be possible ${ }^{14}$. Thus, aluminum powered underwater vehicles show tremendous potential to extend range and endurance compared to current technology.

There are a number of very significant barriers to achieving a 'practical' power system based on $\mathrm{Al} / \mathrm{H}_{2} \mathrm{O}$ combustion. For example, Greiner's system required that molten aluminum be injected into the combustion chamber. This led to a complex and difficult to operate system. An alternative is to inject solid aluminum particles 
but this required complex and bulky seeding systems and the net effect was that research in aluminum-powered underwater propulsion slowed. The aluminumbased underwater propulsion concept was revived in the late 1990's with Pennsylvania State University Applied Research Lab's (ARL) Hybrid Aluminum Combustor (HAC) system $^{9}$ in which an aluminum-sea water combustor provides steam for a Rankine power plant. Considerable work has been performed over the intervening years to develop a reliable aluminum seeder, low pressure drop particle separators, and a reliable combustor that does not slag. These components have been developed at scales suitable for use in small $(10,000 \mathrm{lb}$ class $)$ UUVs. The next step is to construct a prototype system. The objectives of this work are to

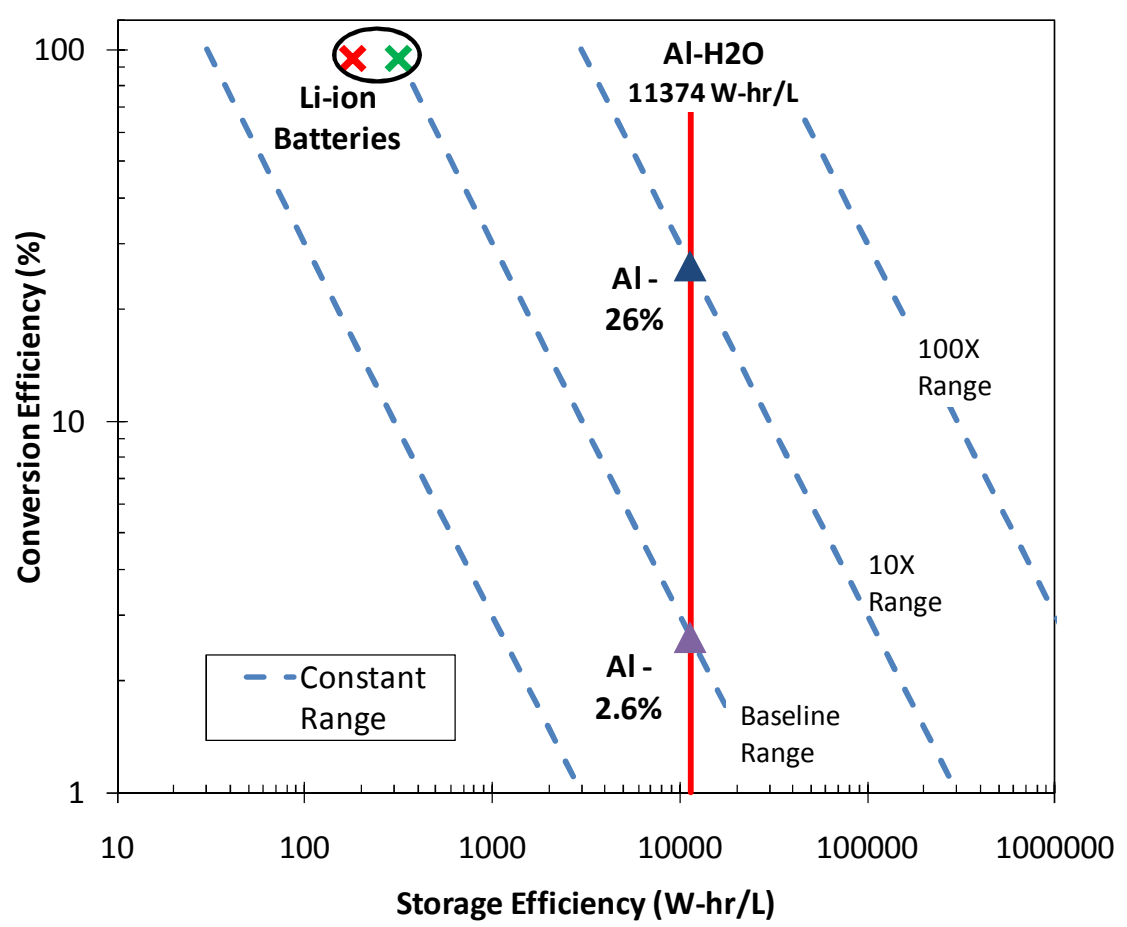

Figure 1. Range increases with fuel energy density and conversion efficiency. develop a thermodynamic model for the complete system in order to estimate its power output and efficiency and to learn something about how to optimize its performance.

\section{B. Propulsion System Concept}

A schematic diagram of the proposed HAC system is presented in Figure 2. The system consists of a fluidized bed fuel seeder in which aluminum powder is suspended by a small flow of gaseous hydrogen $\left(\mathrm{H}_{2}\right)$. The $\mathrm{Al}$ seeded $\mathrm{H}_{2}$ is injected into a pre-combustor where it mixes and reacts exothermically with steam to form $\mathrm{Al}_{2} \mathrm{O}_{3}$ and additional $\mathrm{H}_{2}$. The hot products discharge into the main combustor where quenching water injected along the combustor walls prevents molten alumina particles from attaching to the combustor walls and fouling the system.

This cooling water also evaporates to produce large amounts of steam. The combustion products pass through a cyclonic separator to remove the solid $\mathrm{Al}_{2} \mathrm{O}_{3}$. A splitter diverts a small fraction of the remaining steam/hydrogen mixture into a recirculation loop. This flow is mixed with a small amount of sea water to cool it, compressed, and returned to the pre-combustor to sustain the reaction with incoming aluminum powder. Most of the steam/hydrogen mix passes through the splitter to a turbine that powers the compressor, pumps, and vehicle's propeller. Some of the enthalpy in the flow exiting the turbine is recovered using a heat exchanger which warms the water headed to the

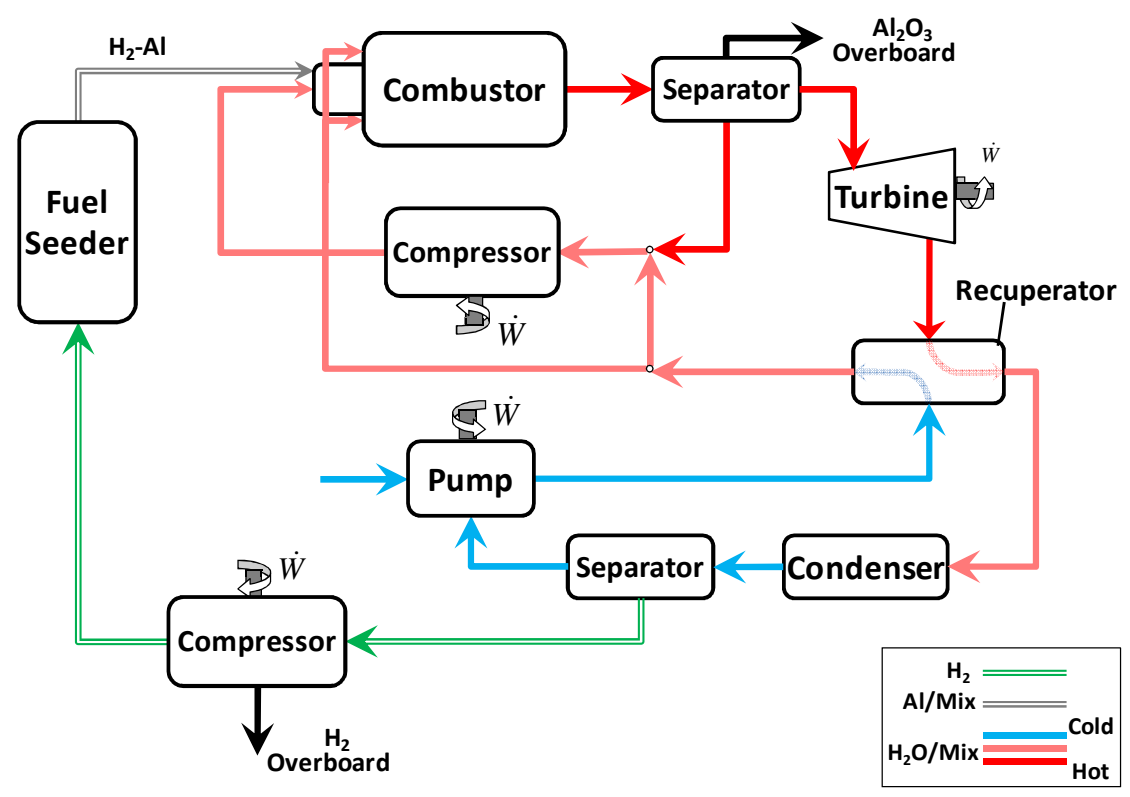

Figure 2. Propulsion system concept schematic. 
main and pre- combustors. The steam is fully condensed to liquid water downstream of the heat exchanger and separated from the $\mathrm{H}_{2}$. A pump draws in an appropriate amount of additional sea water to make up for what is consumed by the combustion process and drives water from the separator back into the system. Some of the hydrogen gas is compressed and fed back into the fuel seeder. However, the combustion process produces much more hydrogen than is needed by the seeder so the remainder is vented overboard. The pressure to which the vented hydrogen needs to be compressed is determined by the vehicle's depth.

\section{Method of Solution}

\section{A. Simulation Environment}

Mathematical models are developed for each component of the system. Each model has inputs, outputs, and parameters that control the operation of the component. The condition of the flow at any point in the model system is described by a number of 'states' representing things like the mass fractions and mass flows of all the species in the system, pressure, density, temperature, water quality, enthalpy, and entropy. The system could be solved by treating each component as a matrix that operates on the incoming state space vector but this approach becomes difficult in systems like the HAC that contain multiple feedback loops and whose components' input-output relationships can be highly nonlinear. Instead, a software package called Numerical Propulsion System Simulation (NPSS $)^{15,16}$ is used to create and solve the system. While NPSS was intended to be a generalized design and analysis tool for developing gas turbine engines, it is equally well-suited for investigations of other systems like the Rankine system of interest here. The principal advantage of NPSS is that it handles the mathematical difficulties associated with solving coupled systems of nonlinear equations and enables the user to focus on developing appropriate component models.

Other advantages of NPSS include its extensive libraries of predefined components, the ability to develop new components easily, and a high degree of flexibility in the types of component models that can be used with it. For example, it is possible to represent a component using a model written in $\mathrm{C}++$ (this is mostly what is done here), a lookup table relating inputs to outputs, or to complex external software like CEA ${ }^{17}$ or CFD simulations like FLUENT ®. System Model

Input and Output 'streams' are NPSS data structures that contain and transfer physical attributes of the flow. These include temperature, pressure, molecular weight, composition, etc. The model developed here uses three different types of streams: Fuel, Flow, and Shaft. Each has its own set of variables and function calls that describes the different attributes of its structure. Figure 3 is a schematic illustration of how information is managed and flows in the NPSS environment. A stream enters a component, has some or all of its attributes changed depending on the physical processes occurring in the component, and exits the component with new values for some or all of its attributes. A stream originates from a 'flow start element' that establishes initial values of the stream's attributes.

'Parameters' (P.1, P.2...P.n) describe fixed attributes of a particular component that do not

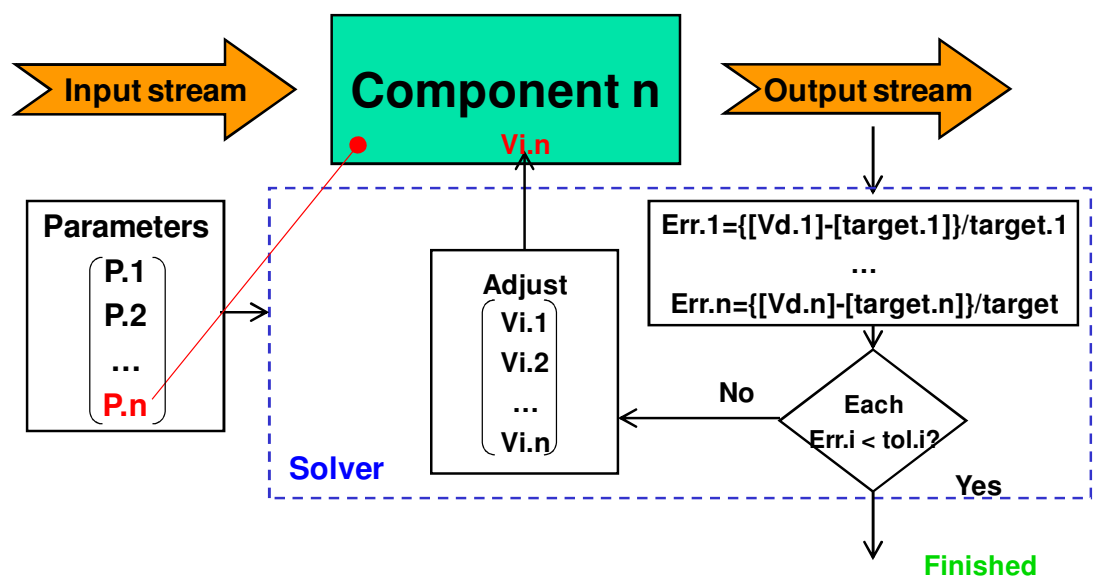

Figure 3. Schematic illustration of a 'generic' NPSS component showing inputs, outputs, parameters, and solver iteration.

change during the solution process. Examples include the turbine efficiency or the flow area of a component. 'Independent Variables' (Vi.1, Vi.2...Vi.n) describe attributes of a particular component that are independently varied/controlled by NPSS in order to achieve a stable solution to the system. The independent variables in the aluminum combustion system are the splitting ratios $(B P R 1, B P R 2)$ of the high temperature separator and the quenching water, and the heat exchanger effectiveness $(\mathcal{E})$. It is also possible to impose maximum and/or minimum constraints that the independent variables can attain. An example would be limiting the temperature of the precombustor. All of the attributes in an output stream are 'dependent variables' (Vd.1, Vd.2...Vd.n) because they are the results of calculations that occurred within the element. 


\section{B. Component Models}

The basic equations describing how the physical processes occurring in each component are represented are outlined below. There are six flow variables of interest in the streams entering and exiting each component: pressure, temperature, mass flow, and composition which includes major species like $\mathrm{H}_{2} \mathrm{O}, \mathrm{Al}_{2} \mathrm{O}_{3}$ and $\mathrm{H}_{2}$, and several more minor species like $\mathrm{OH}, \mathrm{H}$, and atomized aluminum. These variables in turn define the enthalpy and entropy state of the flow. In these equations, the subscript 1 denotes conditions at the upstream boundary of the element, the subscript 2 denotes the downstream boundary of the element, and the subscript 3 denotes the downstream boundary of the secondary outlet stream (if one exists).

\section{Aluminum Seeder}

It is impractical to model the details of the particle entrainment process occurring in the seeder. Instead, the degree of entrainment is assumed to be linearly proportional to the weight flow of $\mathrm{H}_{2}$ gas, scaled by the constant seeding ratio $k_{\text {seed }}$. Mass of hydrogen is conserved, and the aluminum flow is added within the component. Pressure losses are represented using a constant pressure loss parameter.

$$
\begin{gathered}
\dot{m}_{A l, 2}=k_{\text {seed }} \dot{m}_{H_{2}, 1} \\
\dot{m}_{H_{2}, 2}=\dot{m}_{H_{2}, 1} \text { and } \dot{m}_{A l, 1}=0 \\
P_{2}=P_{1}-d P_{\text {seed }}
\end{gathered}
$$

The values of both $k_{\text {Seed }}$ and $d P_{\text {Seed }}$ are selected to reflect measurements made in prototype seeder hardware. The seeder is also assumed to be adiabatic so $T_{1}=T_{2}$.

\section{Combustor}

An equilibrium calculation based on the minimization of Gibbs' free energy is used to determine the composition of the products exiting the combustor and the heat of combustion. The Gibbs free energy of the mixture $\left(g_{\text {mix }}\right)$ is given by:

$$
g_{\text {mix }}=\sum_{j=1} \mu_{j} n_{j}
$$

where $\mu_{j}$ is the chemical potential, $n_{j}$ is number of moles, and $j$ indexes the chemical species under consideration. The pressure at the downstream boundary of the combustor is prescribed before the run and the calculation is performed at constant pressure and enthalpy. The temperature of the products is determined by the heats of formation of the reactants and products and the equilibrium state mixture composition. Reaction rates are not computed. The minimization is performed by CEA and the algorithm is described in detail in the CEA documentation ${ }^{17}$. The mass flow of water entering the pre-combustor is equal to the mass flow of aluminum so the mixture is always stoichiometric. Additional water is added to the main combustor which causes the overall mixture to be 'lean'. The excess water is used to generate steam for the Rankine cycle and to control the combustor exit temperature. The equilibrium assumption provides a 'best-case' estimate of performance. Inhomogeneities in the flow and premature reaction quenching will degrade the performance of the 'real' device but the degree to which this will occur is not known.

\section{Separator}

The separator divides the inlet stream into a primary flow consisting mainly of gaseous $\mathrm{H}_{2}$ and steam, and a secondary flow consisting mainly of $\mathrm{Al}_{2} \mathrm{O}_{3}$ waste. The model assumes that for an ideal process involving $n$ mixture components, the work required to completely separate is equal to the mixing entropy generated at a temperature, $T$, as given by Ref. 18. The work required to partially separate the mixture is equal to the difference between the work required to completely separate the inlet stream and the sum of the work required to completely separate each outlet stream: 


$$
\dot{W}_{S e p}=-R_{u} T \sum_{i=1}^{n}\left[\frac{\dot{m}_{i, 1}}{M W_{i}} \ln x_{i, 1}-\frac{\dot{m}_{i, 2}}{M W_{i}} \ln x_{i, 2}-\frac{\dot{m}_{i, 3}}{M W_{i}} \ln x_{i, 3}\right]
$$

where $R_{u}$ is the universal gas constant, $x_{i}$ is the mole fraction of species $i$, and $M W_{i}$ is molecular weight. The separation efficiency for each species $\left(\eta_{i}\right.$, ) is a fixed parameter. It is defined as the mass flow rate of the $i^{\text {th }}$ species in the waste stream divided by the mass flow rate of the $\mathrm{i}^{\text {th }}$ species in the inlet stream. Applying mass conservation and the definition of separation efficiency gives the following expressions for the mass flow rates of the individual species exiting the separator:

$$
\dot{m}_{i, 2}=\dot{m}_{i, 1}\left(1-\eta_{i}\right) \quad \text { and } \quad \dot{m}_{i, 3}=\dot{m}_{i, 1} \eta_{i}
$$

Equations (9) and (10) are used to compute the composition of the output streams. Then Equation (8) is applied to the inlet and outlet streams to obtain the separation work. Finally, the output enthalpy (or temperature) is determined using conservation of energy for an adiabatic process:

$$
\dot{m}_{2} \sum_{i=1}^{n} x_{i, 2} h_{i, 2}+\dot{m}_{3} \sum_{i=1}^{n} x_{i, 3} h_{i, 3}=\dot{m}_{1} \sum_{i=1}^{n} x_{i, 1} h_{i, 1}-\dot{W}_{S e p}
$$

where $h_{i}$ is the specific enthalpy of species $i$ at the local conditions. The temperatures of the outlet streams are assumed to be equal and are chosen to satisfy Eq. (11).

\section{Turbine}

The pressure ratio across the turbine $\left(P . R_{.}\right)$is another parameter whose value is selected to match that in the prototype HAC system. This leads to the following expression for the pressure downstream of the turbine in terms of the pressure upstream:

$$
P_{2}=\frac{P_{1}}{P \cdot R_{\cdot T}}
$$

The turbine's isentropic efficiency ${ }^{19}\left(\eta_{T}\right)$ is another parameter whose value is selected to match the prototype HAC system. The enthalpy of the flow exiting the turbine is given by:

$$
h_{2}=h_{1}-\eta_{T}\left(h_{1}-h_{2 s}\right)
$$

where $h_{2 s}$ is the ideal exit enthalpy assuming isentropic expansion. The work output of the turbine is the enthalpy difference between inlet and outlet flows. The outlet temperature is computed from the outlet enthalpy and pressure.

\section{Recuperator}

Recuperator performance depends on the effectiveness parameter $(\varepsilon)$ and the pressure drop in each of the fluid streams (P.R.Hot and P.R. Cold $)$. The definition of effectiveness presented in Eq. (14) is valid because $\dot{m}_{H o t} C_{p, H o t}<$ $\dot{m}_{\text {Cold }} C_{p, \text { Cold }}$ is always true in the current simulations.

$$
\begin{aligned}
& \varepsilon=\frac{Q_{\text {actual }}}{Q_{\max }}=\frac{\dot{m}_{\text {Cold }} C_{p, \text { Cold }}\left(T_{\text {Cold }, 2}-T_{\text {Cold }, 1}\right)}{\dot{m}_{\text {Hot }} C_{p, H o t}\left(T_{H o t, 1}-T_{\text {Cold }, 1}\right)} \\
& P . R_{H_{H o t}}=\frac{P_{H o t, 2}}{P_{H o t, 1}} \quad P . R \cdot ._{\text {Cold }}=\frac{P_{\text {Cold }, 2}}{P_{\text {Cold }, 1}}
\end{aligned}
$$


The temperature of the cold side water sets the minimum possible temperature to which the hot gases entering from the turbine can be lowered. The outlet temperature (and enthalpy) of the cold side water stream is calculated using the definition of effectiveness. The hot side exit enthalpy is determined by enforcing energy conservation on the entire recuperator:

$$
h_{H o t, 2}=h_{H o t, 1}+\left(h_{\text {Cold }, 2}-h_{\text {Cold }, 1}\right)\left(\frac{\dot{m}_{\text {Cold }}}{\dot{m}_{\text {Hot }}}\right)
$$

\section{Condenser}

The condenser cools the flow to a specified target temperature (enthalpy) by dumping the requisite amount of heat to the environment. The required heat transfer is given by:

$$
\dot{Q}_{\text {cond }}=\dot{m} \cdot\left(h_{2}-h_{1}\right)
$$

The environment is assumed to be an infinite reservoir so its temperature is assumed to remain constant.

\section{Pump/Compressor}

The pressure ratios across the various pumps and compressor elements in the system are assumed to be known parameters. The exit pressure is given by:

$$
P_{2}=P_{1} \cdot P \cdot R \cdot \cdot_{\text {Pump }}
$$

The power consumption of a pump element is calculated assuming incompressible flow and a specified pump efficiency parameter:

$$
\dot{W}_{\text {pump }}=-\frac{\dot{m} \cdot\left(P_{2}-P_{1}\right)}{\eta_{\text {pump }} \cdot \rho_{\text {water }}}
$$

The compressor exit flow enthalpy is given by:

$$
h_{2}=h_{1}-\frac{\left(h_{1}-h_{2 s}\right)}{\eta_{C}}
$$

In this expression, $\eta_{\mathrm{c}}$ is the isentropic compressor efficiency ${ }^{19}$ (a known parameter in this calculation) and $h_{2 s}$ is the 'ideal' exit enthalpy associated with an isentropic compression process. The value of $h_{2 s}$ is determined in NPSS by a constant entropy CEA calculation at the exit pressure.

The outlet temperature is computed from the outlet enthalpy and pressure. Finally, the power consumption of the compressor is the product of the rate of mass flow through the combustor times the enthalpy difference between the inlet and outlet flows:

$$
\dot{W}_{\text {comp }}=\dot{m} \cdot\left(h_{2}-h_{1}\right)
$$

\section{Splitter}

The HAC system flow path contains two adjustable splitters. The cold-side splitter and the combustion splitter operate to maintain the correct pre-combustor steam temperature and a stoichiometric $\mathrm{Al} / \mathrm{H}_{2} \mathrm{O}$ ratio in the precombustor. Splitter elements function by diverting a single inlet stream into two outlet streams with the same pressure, temperature, and composition as the inlet stream. Energy conservation is implicit in the assumption of constant flow pressure, temperature, and composition. The mass flow split between the streams is set by the bypass ratio $(B P R)$ parameter. 


$$
\begin{gathered}
B P R=\frac{\dot{m}_{3}}{\dot{m}_{2}} \\
\dot{m}_{2}=\frac{\dot{m}_{1}}{1+B P R}
\end{gathered}
$$

\section{HAC System Model}

Figure 4 is a schematic illustration of the HAC system as it is represented in NPSS. There is a small difference between the simulated and 'real' systems. The hydrogen recirculation does not connect back to the aluminum seeder (but the $\mathrm{H}_{2}$ is compressed to its original $700 \mathrm{psi}$ ). This simplification is not expected to have an impact on the predicted power output and efficiency of the system.

Two loop starter elements are required in order to account for the two flow loops that are present in the system. The components in the dashed boxes in Figure 4 are termed 'Mix Loop' elements and their function is to provide initial estimates for the values of the principal flow variables at the entrance to each flow loop. Loop 1 is associated with the main combustor loop of the power system. Loop 2 is associated with the loop that circulates water back to the recuperator and combustor. These are non-physical elements in the sense that they do not have direct analogs in the physical system nor do they change any of the properties of the streams that pass through them. However, they are required in order to allow NPSS to find a solution due to the recursively dependent nature of the flow loops in the system.

The system is solved by choosing a set of dependent variables whose target values are known. These target values are 'state points' of the system. In this work, these are the recirculation loop mass flow rate and temperature, and the temperature of the postrecuperator quenching water. They appear as dark blue text in Figure 4. NPSS computes normalized errors for each of these variables based on the known state point values. There are 9 independent variables and 9 conditions associated with the

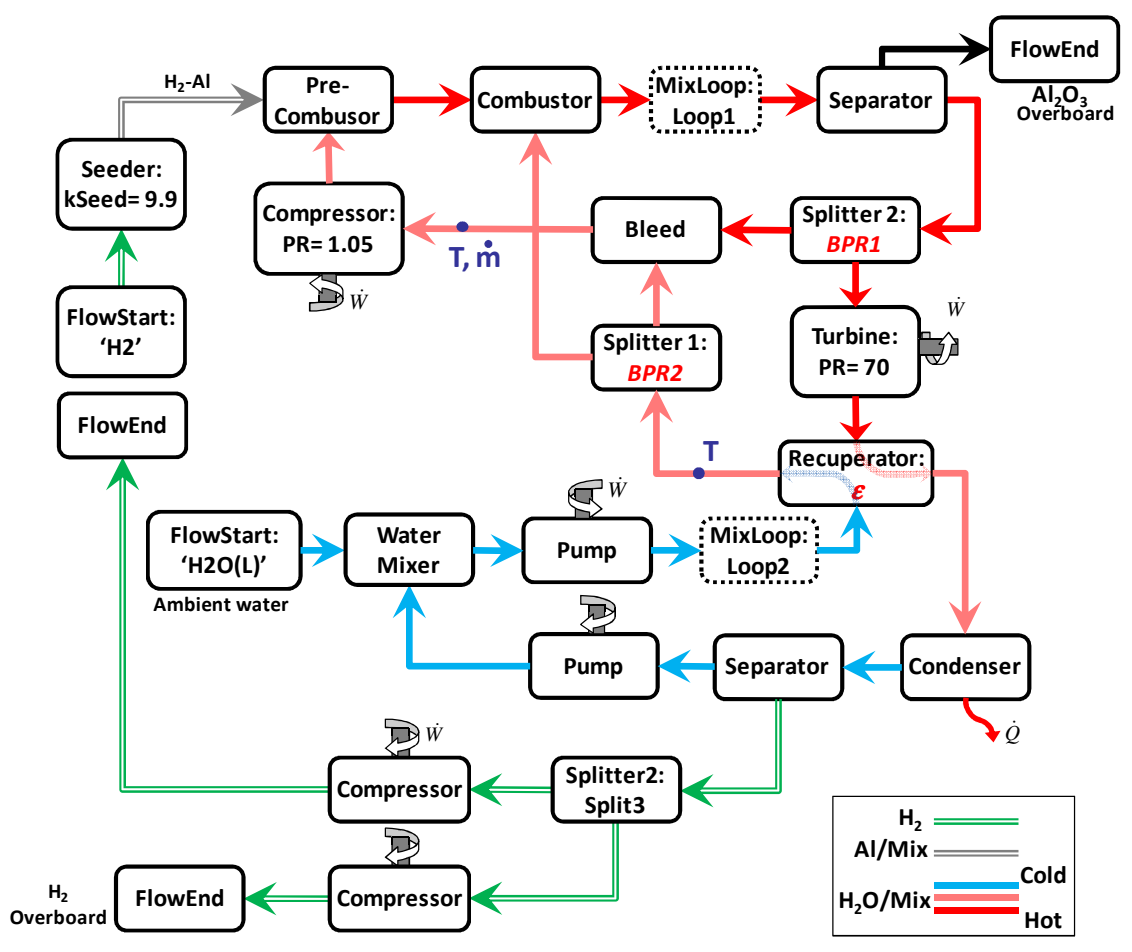

Figure 4: Schematic representation of the system model.

\begin{tabular}{|c|c|}
\hline Independent Variable & Dependent Condition \\
\hline Splitter 1: BPR & Pre-combustor: Steam $\dot{m}_{I N L E T}=$ Aluminum $\dot{m}_{I N L E T}$ \\
\hline Splitter 2: BPR & Pre-combustor: Inlet steam T = Target value \\
\hline Recuperator: $\varepsilon$ & Recuperator: Cold side exit $\mathrm{T}=$ target value \\
\hline Loop 1: $T_{E X I T}$ & Loop 1: $T_{E X I T}=T_{I N L E T}$ \\
\hline Loop 1: $P_{E X I T}$ & Loop 1: $P_{E X I T}=P_{\text {INLET }}$ \\
\hline Loop 1: $\dot{m}_{E X I T}$ & Loop 1: $\dot{m}_{E X I T}=\dot{m}_{I N L E T}$ \\
\hline Loop 1: Exit $y_{\mathrm{H} 2 \mathrm{O}}$ & Loop 1: Exit $y_{\mathrm{H} 2 \mathrm{O}}=\operatorname{Inlet} y_{\mathrm{H} 2 \mathrm{O}}$ \\
\hline Loop 1: Exit $y_{H 2}$ & Loop 1: Exit $y_{H 2}=\ln l e t y_{H 2}$ \\
\hline Loop 1: Exit $y_{A / 2 O 3}$ & Loop 1: Exit, $y_{\mathrm{H} 2 \mathrm{O}}+y_{\mathrm{H} 2}+y_{\mathrm{A} / 2 \mathrm{O} 3}=1$ \\
\hline Loop 2: Exit $y_{\mathrm{H} 2 \mathrm{O}}$ & Loop 2: Exit $y_{\mathrm{H} 2 \mathrm{O}}=\operatorname{Inlet} y_{\mathrm{H} 2 \mathrm{O}}$ \\
\hline Loop 2: Exit $y_{A 12 O 3}$ & Loop 2: Exit, $y_{\mathrm{H} 2 \mathrm{O}}+y_{\mathrm{Al} 2 \mathrm{O} 3}=1$ \\
\hline Condenser: $T_{E X I T}$ & Loop 2: $T_{E X I T}=T_{I N L E T}$ \\
\hline
\end{tabular}

Table 2. Independent variables and dependent conditions.

9

American Institute of Aeronautics and Astronautics 
flow start elements. There are 3 independent variables and 3 conditions associated with physical HAC system (these are the bypass ratios across the splitters and $\varepsilon$ ). This gives a total of 12 independent variables and 12 conditions associated with the HAC model. The variables and dependent conditions are summarized in Table 2. NPSS uses a Newton Rhapson method ${ }^{15}$ to solve the system by adjusting the values of the 12 independent variables in order to drive the 12 error terms to zero thereby satisfying the 12 dependent conditions.

Constraints can be applied during this process to represent physical limitations of the system such as maximum burner output temperature. Additional description of the solution process is presented elsewhere ${ }^{15,20}$.

\section{Model Operating Cases}

The system is initialized with a set of design conditions $\left(\mathrm{Al}\right.$ and $\mathrm{H}_{2} \mathrm{O}$ mass flows, component efficiencies, pressure ratios, and temperature set points) and also with estimates for the 3 design parameters and 9 parameters associated with the flow start elements. An important limitation of the Newton-Rhapson approach is that these estimates cannot be too bad or the solution will rapidly diverge from the desired state. Two sets of proposed operating points for the prototype were used to initialize the model. These will be referred to as Case 1 and Case 2 and are summarized in Table 3 . The feed water temperatures are chosen consistent with Office of Naval Research guidelines ${ }^{21,22}$ for UUV operating environments. The mass flow rates were chosen to be consistent with $10-20 \mathrm{~W} / \mathrm{L}^{21}$ power density in a large class UUV ${ }^{1}$ with a roughly $1000 \mathrm{~L}$ energy section. In general, Case 1 calls for higher temperatures and mass flows but makes more pessimistic assumptions about pressure loss and turbine efficiency. The NPSS model was run for both Cases to find the stable system operating points associated with each. In The converged value of heat exchanger effectiveness is limited

Table 3. Operating point comparison.

\begin{tabular}{|l|r|r|}
\hline Temperatures (R ) & \multicolumn{1}{c|}{ Case 1 } & \multicolumn{1}{c|}{ Case 2 } \\
\hline Recirculation loop & 1360 & 1259 \\
\hline Quenching water & 725 & 619 \\
\hline Feed water & 565 & 529 \\
\hline
\end{tabular}

Mass flow (lb/s)

\begin{tabular}{|l|r|r|}
\hline Recirculation loop & 0.0388 & 0.0297 \\
\hline Aluminum fuel & 0.0388 & 0.0297 \\
\hline Feed Water & 0.155 & 0.1292 \\
\hline
\end{tabular}

Pressure ratio

\begin{tabular}{|l|r|r|}
\hline Recuperator & 0.8 & 0.95 \\
\hline Condenser & 0.75 & 0.947 \\
\hline
\end{tabular}

\begin{tabular}{|l|l|l|}
\hline Turbine efficiency & $60 \%$ & $70 \%$ \\
\hline
\end{tabular}
to $0<\varepsilon<1$, and the splitter bypass ratios are limited to $B P R>0$. The thermodynamic efficiency and net power output associated with each case are computed from the converged solutions.

\section{Results}

\section{A. Design Point Performance Comparison}

Figure 5 is a bar chart comparing Case 1 and 2 performance on the basis of net power output of the system, overall thermodynamic efficiency (Equation 25), and specific fuel consumption (SFC) (Equation 26).

$$
\begin{gathered}
\eta_{t}=\frac{\text { Net Power Output }}{\text { Chemical Energy Input }}=\frac{\dot{W}_{\text {turb }}-\dot{W}_{\text {comp }}-\dot{W}_{\text {pump }}}{\dot{m}_{\text {reax }} \cdot \Delta H_{\text {reax }}} \\
S F C=\frac{\text { Fuel Mass Flow }}{\text { Net Power Output }}=\frac{\dot{m}_{\text {reax }}}{\dot{W}_{\text {turb }}-\dot{W}_{\text {comp }}-\dot{W}_{\text {pump }}}
\end{gathered}
$$

Figure 5 also compares temperature and mass flows through the combustor and turbine. The results show that Case 1 produces $32 \%$ less net power despite producing $24 \%$ more turbine power. The increased turbine power makes sense given the higher mass flow through the turbine and is the result of differences in the prescribed conditions. The reason Case 1 has lower net power is due to the parasitic power demands of the hydrogen compression. Both cases require a significant fraction of the turbine power to drive the compressors, but because the hydrogen to steam ratio is more than $11 \%$ higher in Case 1 than in Case 2, the parasitic losses associated with that hydrogen are much greater. As a result, Case 2 is much more efficient.

It is additionally worth noting the effect of operating condition on the turbine specific work. Surprisingly the two cases are nearly equal in this respect despite the fact that Case 2's turbine isentropic efficiency is significantly greater than that of Case 1. To understand why, consider the equation for turbine power ${ }^{23}$ : 


$$
\frac{\dot{W}_{t u r b}}{\dot{m}}=C_{p} T_{1} \eta_{T}\left[1-\left(P_{2} / P_{1}\right)^{\frac{\gamma-1}{\gamma}}\right]
$$

Case 1 has higher temperatures throughout the system including the turbine and which Eq. (27) shows that this will result in increased work output. In addition, the increased hydrogen to steam ratio in Case 1 will cause an increase. Since hydrogen's specific heat capacity $\left(C_{p}\right)$ is several times higher than steam's, relatively small changes in the hydrogen gas mass fraction can have a significant impact on $C_{p}$ of the mixture and thus the work output.
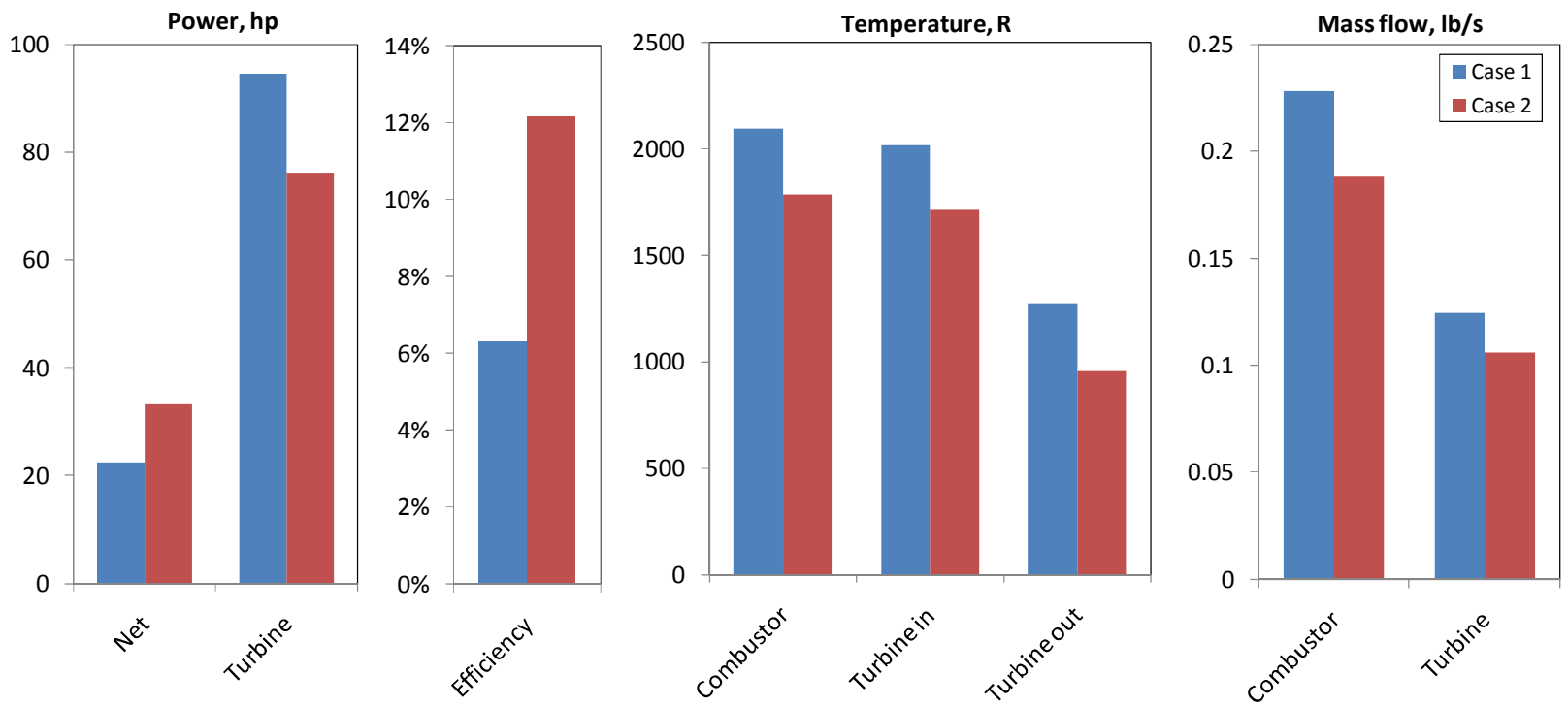

Figure 5. Power output, efficiency, and flow states at Case 1 and Case 2 operating points.

\section{B. Effect of varying operating point conditions}

The calculations described above can only give a snapshot of expected system performance for the operating points specified in Cases 1 and 2. However, these points may not be the best. Therefore, it is important to understand how system performance is affected by changing the design or operating condition. A true "off-design" analysis is beyond the scope of this work as it requires a proper accounting of loss mechanisms and how operational changes will affect them. For example, the current model does not account for the variation of heat and friction losses or the change in turbine efficiency as flow rates change. However, it is possible to determine how changing the values of these operating parameters impacts system power output and efficiency. While there are many parameters that could be varied, we will focus on two that the preliminary analyses suggest are very important: aluminum fuel mass flow (which should be directly related to the turbine power output) and the feed water mass flow (which will influence the combustor temperature and flow composition).

The fuel mass flow rate is varied over the full range for which a converged solution exists. The limits occur where the heat exchanger effectiveness or splitter bypass ratios fall outside of their allowed ranges $(0<\varepsilon<1$, $0<B P R<\infty)$. For example, at lower operating temperatures the 'hot' side of the heat exchanger lacks the enthalpy to raise the 'cold' side to the target warmed water temperature and a solution is not possible. An

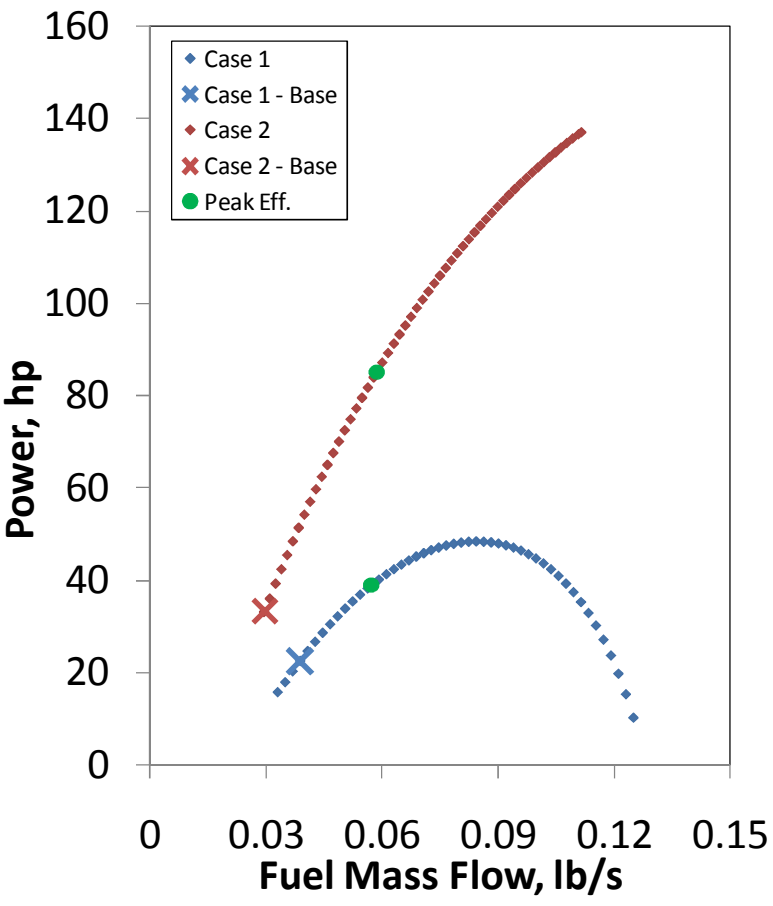

Figure 6. Power output as fuel flow rate varies. 
additional constraint requires the system to produce positive net work. Converged solutions may exist for such operating points, but the system is no longer thermodynamically viable and therefore has no meaning for the physical system.

Since the Newton-Rhapson method used by NPSS has difficulty converging if the initial guess is too far off, the range of mass flows is explored by marching slowly away from the design point solution. The idea is to perturb the mass flow of aluminum by a small amount, allowing NPSS to converge to new values of the bypass ratio and heat exchanger effectiveness that satisfy the governing equations, saving this solution and using it to set the initial conditions for the next perturbation of the aluminum flow. This method works as long as the solution space is free of large discontinuities.

The minimum aluminum flow rate for Cases 1 is $85 \%$ of its base value. Case 2 cannot reduce fuel flow rate and reach a converged solution. Cases 1 and 2 have a maximum fuel flow rates of $323 \%$ and $375 \%$ of base values, respectively.

Figure 6 shows the system power output as a function of fuel mass flow rate and Figure 7 shows specific fuel consumption and efficiency as a function of fuel mass flow rate. The non-linear variation of power with fuel flow rate is a consequence of the non-linear variation of the efficiency. Figure 7 also shows that different fuel flow rates maximize efficiency in Cases 1 and 2. The reason for the peaks is as follows: As the fuel mass flow rate increases, a larger fraction of the mass flow from each splitter element must be diverted to the recirculation loop in order to maintain stoichiometric combustion in the pre-combustor. This reduces the amount of quenching water entering the main combustor which in turn leads to higher combustor temperatures and increased hydrogen mass fractions. Both of these effects tend to raise the overall efficiency of the cycle. However, increasing the recirculation flow rate increases the load on the recirculation pump and the elevated turbine exit temperature requires decreased heat exchanger effectiveness which lowers overall efficiency. Most importantly, higher hydrogen fractions result in increased compressor power demand. The competition between these two effects leads to the peak in the efficiency.

The Case 1 results show that peak efficiency occurs at approximately $148 \%$ of the base fuel flow rate. This operating condition also represents a $73 \%$ increase in net power output and an efficiency improvement from $6.3 \%$

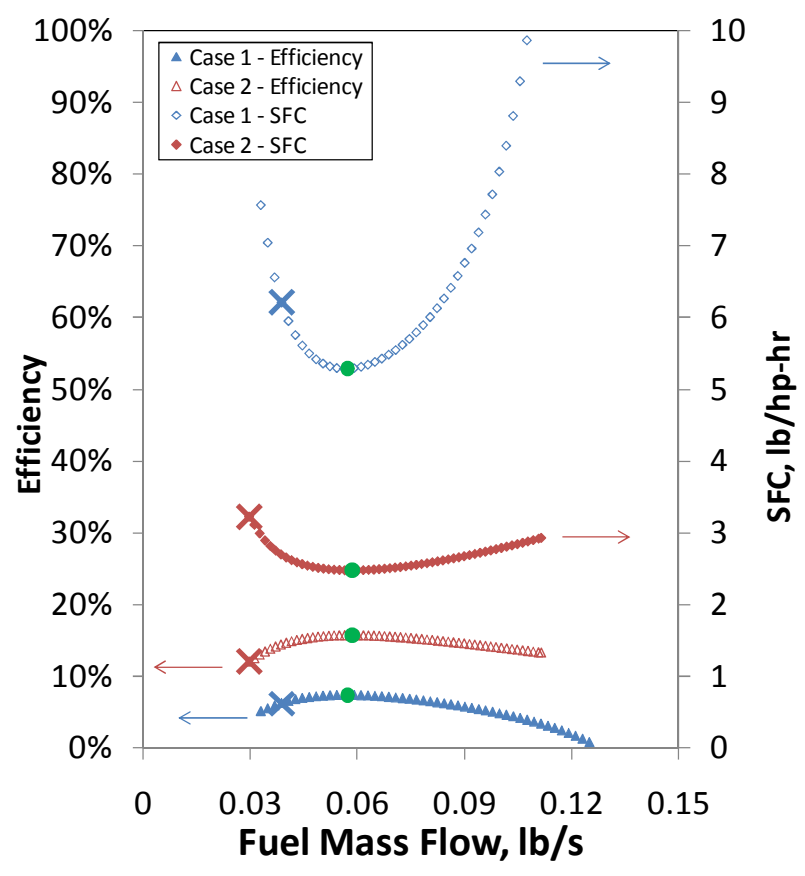

Figure 7. Efficiency as fuel flow rate varies.

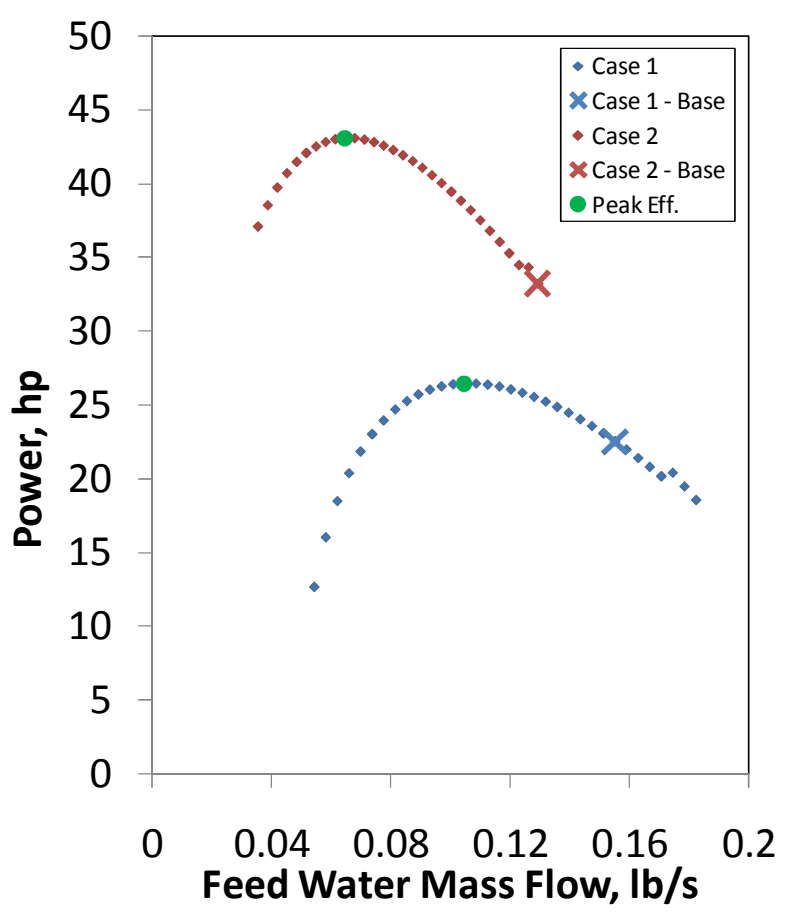

Figure 8. Power output as feed water flow varies.

to $7.4 \%$. The Case 2 results show that peak efficiency occurs at approximately $198 \%$ of the base fuel flow rate. This results in a 156\% increase in net power and an improvement in efficiency from $12.1 \%$ to $15.7 \%$. It should be noted that in practice, operation at peak efficiency may exceed the thermal limits of the combustor materials. 
The cooling water flow rate is similarly limited by the constraints on $\varepsilon$ and $B P R$. In Case 1, the cooling water flow rate ranges from $35 \%$ to $118 \%$ of the base mass flow. In Case 2, the cooling water flow rate ranges from $28 \%$ to $100 \%$ of the baseline.

Figure 8 and Figure 9 show the variations of power output and fuel efficiency with cooling water flow rate. Figure 8 shows that there is a well-defined peak in the power output. Since the fuel flow rate is held constant, the plots of power output and efficiency track each other and the peak power and efficiency points coincide. Optimum efficiency occurs at $67 \%$ of the baseline feed water mass flow rate in Case 1 and at $50 \%$ of the baseline value in Case 2. The peak efficiency states for Case 1 and Case 2 are identical to those found by varying fuel mass flow in all respects except for total mass flow and power.

The peak in efficiency is a result of a trade between combustor temperature and flow heat capacity vs. turbine mass flow rate and parasitic losses: At the minimum feed water flow condition described above, $B P R 2$ approaches infinity which means that all of the feed water reacts with aluminum in the pre-combustor.

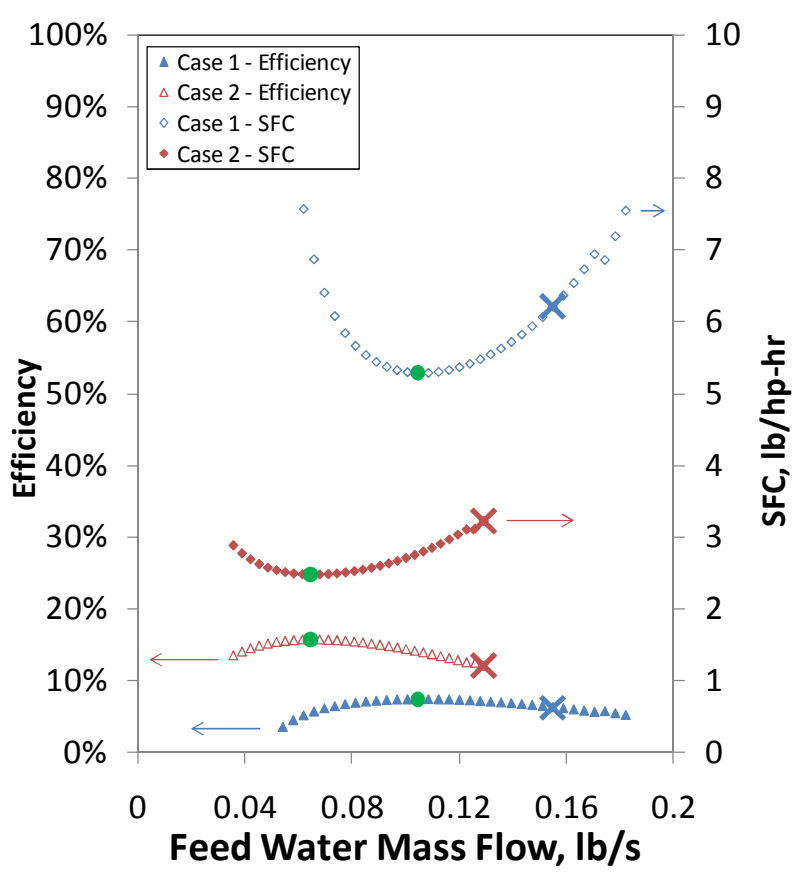

Figure 9. Efficiency as feed water flow varies.

This leads to maximum combustor temperature and $\mathrm{H}_{2}$ mass fraction but minimum turbine mass flow and high parasitic compressor demand. At the maximum feed water flow condition, the bypass ratio approaches zero which means that all of the feed water goes to quenching the combustor and the combustor exit temperature equals the target recirculation temperature value. This condition leads to the minimum combustor temperature and $\mathrm{H}_{2}$ mass fraction but the maximum turbine mass flow. The peak efficiency occurs between these two extremes where the effects of the combustor temperature and turbine mass flow are in balance.

\section{Discussion}

Something remarkable is observed when the state points of the system at the peak efficiency conditions discussed above are compared: The heat exchanger effectiveness, splitter BPRs, flow composition, and temperatures are identical. The only things that are different are the mass flow rates and power output. This suggests that the variation of system performance is best described by the ratio of feed water to fuel mass, rather than the two parameters separately. This is confirmed in Figure 10 which shows efficiency as a function of the feed water to fuel mass ratio for Cases 1 and 2. The effects of varying the fuel and feed water mass flow rates collapse to a single curve indicating that their ratio is really the parameter that is important. The figure shows that the optimum feed water to fuel mass flow rate is approximately 2.7:1 for Case 1 and approximately 2.2:1 for Case 2. This means that optimum

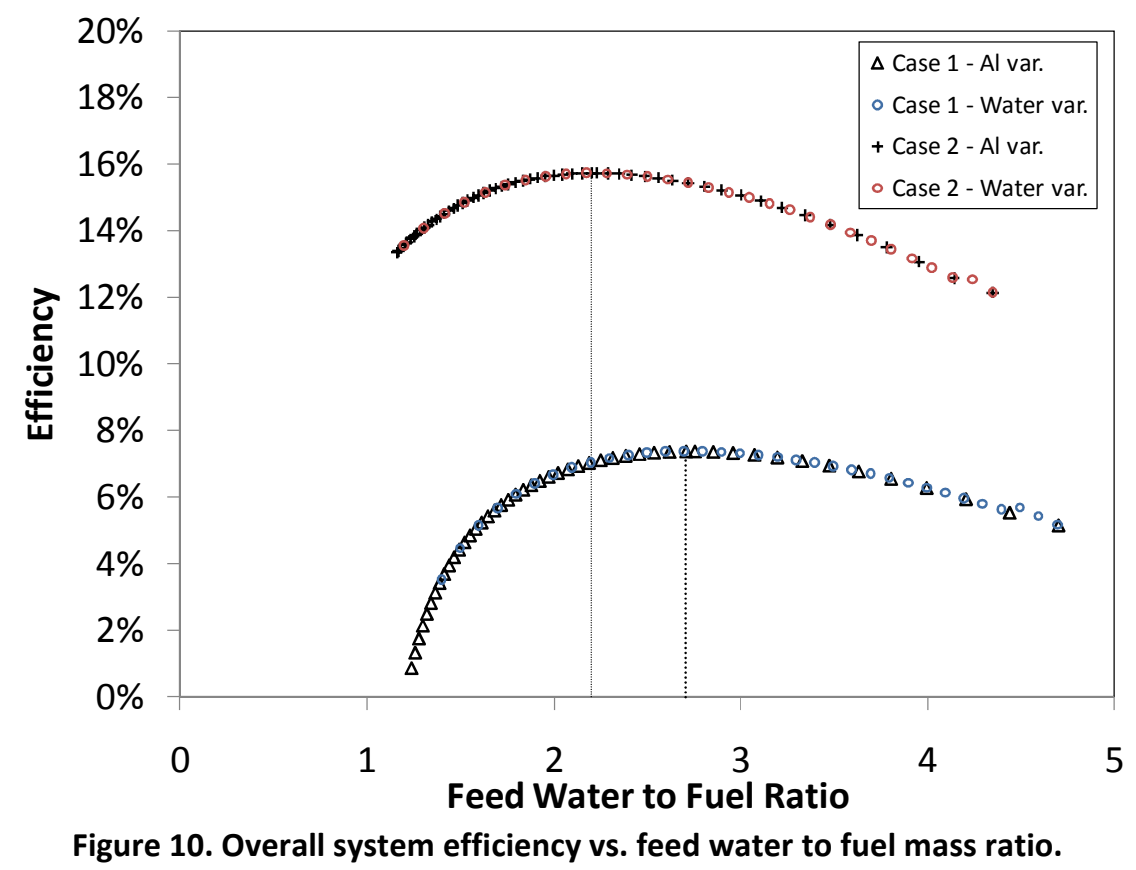

13

American Institute of Aeronautics and Astronautics 
performance can be achieved at any power level (set by the fuel mass flow rate alone) as long as the fuel to feed water ratio is held constant and the resulting temperatures don't exceed material limits.

\section{Conclusions and Future Work}

A numerical model of a novel underwater propulsion system based on the Rankine cycle and the exothermic reaction of aluminum powder with sea water has been developed using the system modeling tool NPSS. The analysis indicates that the system appears to be capable of producing the power levels consistent with at least 10-20 $\mathrm{W} / \mathrm{L}^{21}$ power density in a large class $\mathrm{UUV}^{1}$ with a roughly $1000 \mathrm{~L}$ energy section at efficiencies high enough to yield a several-fold increase in range. However, the performance of the real system will be lower because of frictional losses associated with connecting tubes and other highly design-dependent factors that were not possible to address in this study. One of the most important findings is that peak operating efficiency can be maintained at any power setting as long as the ratio of the feed water to fuel mass flow rates remains constant. Another important finding is that the parasitic power required to compress the waste hydrogen so that it can be dumped overboard can be very large depending on the depth at which the vehicle operates. Dumping waste hydrogen overboard may also be undesirable for reasons of stealth. Future work is required to perform a more complete sensitivity analysis of the system, to incorporate thermal and frictional losses in the tubes connecting components and within the components themselves, to develop strategies for reducing the losses associated with disposal of the waste hydrogen, and to predict the volumetric energy density of a HAC system. The latter is the key parameter that determines the competitiveness of the HAC concept.

\section{Acknowledgments}

The authors would like to thank Ms. Maria Medeiros of the Office of Naval Research for supporting this work, Dr. Joe Fontaine of the Naval Undersea Warfare Center - Newport Branch for helping us to understand the unique requirements of underwater operations and Mr. Tom Lavelle of the NASA Glenn Research Center for help with NPSS. W. Ethan Eagle performed this research while a graduate research assistant at the University of Maryland.

\section{References}

1"The Navy unmanned undersea vehicle (UUV) master plan," Department of the Navy, 2004.

${ }^{2}$ Waters, D.F., "Modeling of water-breathing propulsion systems utilizing the aluminum-seawater reaction and solid-oxide fuel cells," M.S. Thesis, University of Maryland, College Park, MD, 2011.

${ }^{3}$ Lakeman, J.B., Rose, A., Pointon, K.D., Browning, D.J., Lovell, K.V., Waring, S.C., Horsfall, J.A., "The direct borohydride fuel cell for UUV propulsion power," Journal of Power Sources, Vol. 162, 2006, pp.765-772.

${ }^{4}$ Gitzendanner, R., Puglia, F., Martin, C., Carmen, D., Jones, E., Eaves, S., "High power and high energy lithium-ion batteries for under-water applications," Journal of Power Sources, Vol. 136, 2004, pp.416-418.

${ }^{5}$ Greiner, L., "Torpedo propellants," Underwater Missile Propulsion, edited by L. Greiner, Compass Publications, Arlington, VA, 1967, pp. 269-279.

${ }^{6}$ White, W.D., "Lithium and sodium as water-reactive fuels for torpedo propulsion," Underwater Missile Propulsion, edited by L. Greiner, Compass Publications, Arlington, VA, 1967, pp. 281-288.

${ }^{7}$ Roy, G., Advances in Chemical Propulsion: Science to Technology, CRC Press, Boca Raton, FL, 2001.

${ }^{8}$ Carmichael, B.H., "Underwater drag reduction through optimum shape," Underwater Missile Propulsion, edited by L. Greiner, Compass Publications, Arlington, VA, 1967, pp. 147-169.

${ }^{9}$ Miller, T.F., Walter, J.L., Kiely, D.H., "A next generation AUV energy system based on aluminum-seawater combustion," Workshop on Underwater Vehicles, June 20-21, 2002.

${ }^{10}$ Fricke, H.D., Burr, J.W., Sobienick, M.G., "Fluidized powders - A new approach to storable missile fuels," $12^{\text {th }}$ JANNAF Liquid Propulsion Meeting, Vol. 201, CPIA, 1970, p. 393.

${ }^{11}$ Swihart, M.T., Catoire, L., "Thermochemistry of aluminum species for combustion modeling from $a b$ initio molecular orbital calculations," Combustion and Flame, Vol. 121, 2000, p. 210.

${ }^{12}$ Linden, D., Reddy, T.B., Handbook of batteries, $6^{\text {th }} e d$. ., McGraw-Hill, New York, 2002, p. 1.16.

${ }^{13}$ Greiner, L., Hansen, F.A., “A sea-water-aluminum torpedo propulsion system," Underwater Missile Propulsion, edited by L. Greiner, Compass Publications, Arlington, VA, 1967, pp. 289-299.

${ }^{14}$ Kiely, D.H., "Review of underwater thermal propulsion," AIAA/ASME/SAE/ASEE Joint Propulsion Conference \& Exhibit, Indianapolis, IN, June 27, 1994.

15 "NPSS user guide, software release 1.6.5," NASA, 2008.

16"NPSS developer's guide, software release 1.6.5," NASA, 2008.

${ }^{17}$ Gordon, S., McBride, B., “Complex Chemical Equilibrium Compositions and Applications,” NASA RP-1311, 1994.

${ }^{18}$ O'Connell, J.P., Haile, J.M., Thermodynamics: Fundamentals for Applications, Cambridge University Press, New York, 2005, p.130. 
${ }^{19}$ Hill, P.G., Peterson, C.R., Mechanics and Thermodynamics of Propulsion, Addison-Wesley Publishing Company, Reading, MA, 1965, p.162.

${ }^{20}$ Eagle, W.E., "Modeling of a high energy density propulsion system based on the combustion of aluminum and steam," M.S. Thesis, University of Maryland, College Park, MD, 2007.

21 "Long endurance undersea vehicle propulsion," Office of Naval Research BAA \#11-016, March 31, 2011.

22"Large displacement unmanned underwater vehicle innovative naval prototype energy section technology," Office of Naval Research BAA \#11-028, August 4, 2011.

${ }^{23}$ Cengel, Y., Boles, M., Thermodynamics: An Engineering Approach 4th ed., McGraw-Hill, New York, 2002. 